\title{
The Place of Chinese Doramas in the Russian Socio-Cultural Landscape
}

\section{Zhou Lixia}

Hainan Professional College of Economics and Business. Haikou, China. Email: nomail[at]nomail.com

\section{Abstract}

The increasing interest of people around the world towards the popular cultures of China, Korea and Japan leads researchers to question how these countries influence the socio-cultural spaces of other countries through the export of their mass culture products.

This study focuses on the analysis of Chinese doramas in the Russian sociocultural space. The increasing number of online fan communities, the activity of translators and dubbers of Chinese TV series, and the widespread use of the Internet in Russia make Chinese dramas easily accessible to a wide audience. Using quantitative methods, the author of the study came to the conclusion that people in Russia are very interested in Asian cultures, and audiences of Asian TV series are growing at a tremendous rate every year. While Korean dramas remain the most popular in Russia, Chinese serials have great competitive potential against their Korean and Japanese counterparts.

This article may be useful to all researchers of mass and popular culture and television series.

\section{Keywords}

Russia; China; Korea; Japan; Doramas; Anime; Manga; Popular Music; TV Series 


\title{
Место китайских дорам в российском социокультурном пространстве
}

\author{
Лися Чжоу \\ Хайнаньский профессиональный колледж экономики и бизнеса. Хайкоу, Китай. \\ Email: nomail[at]nomail.com
}

\section{Аннотация}

Растущий интерес людей по всему миру к популярным культурам Китая, Кореи и Японии заставляет исследователей задаться вопросом, как эти страны через экспорт своих продуктов массовой культуры влияют на социокультурные пространства других стран.

Данное исследование посвящено анализу китайских дорам в российском социокультурном пространстве. Резко возросшее количество сетевых фанатских сообществ, активизация команд по переводу и озвучке китайских телесериалов, а также широкое распространение Интернета в России делают китайские дорамы легкодуступными для широкой аудитории. Использовав количественные методы, автор исследования пришла к выводу, что интерес россиян к азиатским культурам довольно высок, а просмотры азиатских телесериалов с каждым годом растут огромными темпами. Самыми популярными дорамами в России остаются корейские, но китайские сериальные продукты имеют большой конкурентоспособный потенциал в отношении корейских и японских аналогов.

Данная статья может быть полезна всем исследователям массовой и популярной культур и телевизионных сериалов.

Ключевые слова

Россия; Китая; Корея; Япония; дорамы; аниме; манга; популярная музыка; телесериалы

Это произведение доступно по лицензии Creative Commons «Attribution» («Атрибуция») 4.0 Всемирная 


\section{Введение}

Невероятными темпами азиатская массовая культура завоёвывает себе новых поклонников по всему миру, о чём свидетельствуют и большой рост так называемых сетевых фандомов (фанатских сообществ), и упоминания в социальных сетях различных явлений, связанных с азиатской музыкой или телесериалами. Так, например,

Одним из самых обсуждаемых явлений 2019 г. в «Твиттере» оказался жанр современной музыки (и не только музыки) - К-рор. В социальной сети этому тегу было посвящено в общей сложности 6,1 млрд. твиттов (Якушенкова \& Алиев, 2020, с. 189)

При этом интерес поклонников растёт не только по отношению к азиатской музыке: аниме, косплей, манга, дорамы, кинофильмы жанра уся и многие другие продукты поп-культуры Японии, Кореи и, конечно же, Китая, прочно вошли в мировую массовую культуру, детерминируя новые явления и выкристаллизовывая уникальные процессы внутри других культур. Всё это превращает центры Дальневосточного азиатского региона в места паломничества фанатов со всего мира. К тому же сами страны, производящие подобные продукты, заинтересованы в их развитии и экспорте. Например, в 2014 году правительство Южной Кореи выделило 1\% своего годового бюджета на развитие индустрии поп-культуры (Leong, 2014), что в итоге принесло более 1 миллиарда долларов дохода. В последующие годы финансирование будет только увеличиваться.

Кроме Кореи и Японии важным экспортёром продуктов массовой культуры на Запад на сегодняшний день является Китай, который пытается не отставать от своих азиатских коллег, а в некоторых аспектах даже перегоняет. Голливуд планомерно наполняется фильмами и сериалами с китайской тематикой, так как сам Китай является важнейшим рынком сбыта продукции «фабрики грёз» (диснеевский «Мулан», «Шан-Чи: легенда девяти колец» и т.д.). Но в тоже время и Китай довольно удачно экспортирует собственную продукцию на западных рынок, в том числе в Россию.

С началом популярности корейских дорам ${ }^{1}$, их китайский аналог со свойственной ему содержательной частью довольно неплохо начал завоёвывать место в культурной индустрии своего северного соседа. Этот факт заставляет нас задуматься о влиянии китайских дорам на социокультурное пространство России, что, в свою очередь, позволит дать определённую оценку конкурентоспособности китайской телевизионной продукции на международном рынке.

Стоит отметить, что китайские телесериалы в России хоть и представлены официально на крупнейших стриминговых платформах (например,

1 Изначально японский термин, который впоследствии стал использоваться в русскоязычном интернете как общее название для телесериалов, выпускаемых в Восточной Азии 
Кинопоиск) («Сериалы 2020 - Кинопоиск», 2020)', по большей части в России они живут на фанатской любви, благодаря сетевым сообществам, а также переводческим командам, которые занимаются переводами и озвучкой чаще всего бесплатно. Но сам факт существования довольно больших фансообществ в социальных сетях говорит о большой популярности китайских дорам.

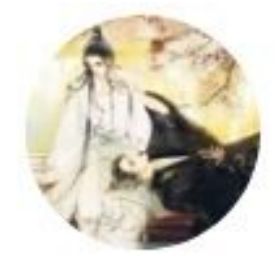

\section{ERHA}

Закрытая группа

11876 участников

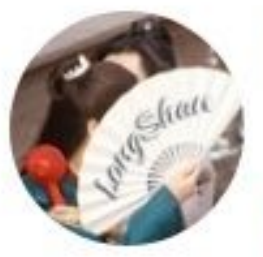

Erha | TGCF

Открытая группа

200

3 друга $\cdot 21977$ участников

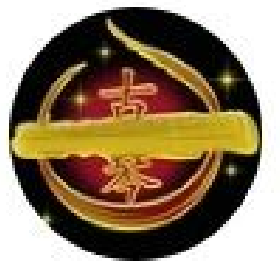

Уголок Гуциня ※ Благословение

небожителей

Открытая группа

8310 участников

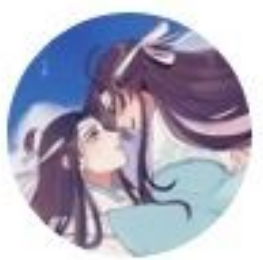

Mo Dao Zu Shi | Основатель тёмного пути

Открытая группа

\section{1 участник}

Рисунок 1. Скриншоты фанастких сообществ любителей китайских дорам в российской социальной сети BK

Figure 1. Screenshots of fan communities of Chinese drama fans in the Russian social network VK

На рисунке 1 представлены некоторые фанатские сообщества российской социальной сети ВК (Вконтакте). На скриншотах видно в том числе и количе-

1 Здесь хотелось бы отметить, что и сами китайские платформы нередко предоставляют русские субтитры к сериалам, и происходит это порой при помощи фанатов. 
ство участников таких сообществ. И хотя их число невелико в контексте самой социальной сети, говорить о том, что оно маленькое, нельзя.

\section{Степень разработанности}

Не трудно догадаться, что большая популярность продуктов азиатской популярной культуры не может не порождать новые процессы и явления как внутри собственных азиатских культур, так и других (в том числе и западных). А так как эти процессы и явления сильно влияют и на локальные культуры, и на общий культурный ландшафт целых регионов, то на сегодняшний день существует огромный пласт научных исследований, предметом которых и выступают те или иные проблемы социокультурного развития в контексте влияния азиатской массовой культуры.

Исследовательские работы, затрагивающие проблемы китайских дорам в социокультурном пространстве России, к сожалению, отсутствуют, но имеется большой пласт работ, посвящённых научным изысканиям популярной культуры Китая. Анализ их содержания позволяет нам наметить вектор данного исследования, которое будет опираться на методологический базис предшествующих работ.

В 2018 году веб-сериал под названием «Хранитель» (镇魂) быстро привлёк внимание в китайском Интернет пространстве, отмеченный феноменальной популярностью и горячим продвижением его фанатами, которые были в основном молодые женщины, известные как «девушки-хранительницы» (镇魂女 孩). Всего через 2 дня после премьеры «Хранителя» 13 июня на самой популярной в материковом Китае потоковой видеоплатформе Youku, количество просмотров превысило 100 миллионов; в финальном эпизоде количество просмотров достигло 2,7 миллиарда. (“Chunxi Road” 2018). Согласно статистике, опубликованной на официальном аккаунте Guardian в Weibo , к моменту выхода в эфир финала у аккаунта было почти миллион подписчиков и было почти 17 миллионов сообщений с хэштегом «веб-сериал Хранитель» (剧版镇魂), набрав 11 миллиардов просмотров (Ng \& Li, 2020, р. 479). В 2020 ряд исследователей из университета Огайо (США), проводя анализ этого феномена, пришли к выводу, что этот сериал сигнализирует о появлении новых гендерных норм, идущих в разрез с официальной китайской идеологией, а борьба с подобной продукцией есть борьба с меняющимся обществом (по крайней мере в аспекте гендера). Таким образом и возникает конфликт между этими субъектами (Ng \& $\mathrm{Li}$, 2020).

В контексте влияния корейской поп-культуры на туристические предпочтения китайцев и русских стоит отметить работу ряда исследователей из университета Ёнсе (Сеул, Южная Корея) (Whang, Yong, \& Кo, 2016). В ней «концепция вовлеченности в поп-культуру применяется к туристическому дискурсу» (Whang, Yong, \& Ko, 2016, p. 631). Авторы опубликованной статьи классифицировали вовлечённость в корейскую поп-культуру на различных 
уровнях в отношении влияния этой вовлечённости на туристические предпочтения (р. 631). К тому же исследователи отметили разницу в структурных туристических моделях России и Китая, что по их мнению определяется национальными предпочтениями (р. 639).

Работа Сяо Ху из Гонконгского университета (Китай) под названием «Настроение китайской поп-музыки: репрезентация и распознование» (ориг. "The Mood of Chinese Pop Music: Representation and Recognition") посвящено исследованию настроений в китайской популярной музыке (C-Рор). При этом Сяо Ху проводит сравнение пространств настроения между китайской и западной поп-музыкой, что «продемонстрировало высокую согласованность между ними, а также отчетливые и заметные кластеры "спокойное", "успокаивающее", "расслабленное" настроение в музыке C-Pop» (Hu \& Yang, 2017, p. 1900).

Сяо Ху не единственный исследователь популярной китайской музыки. В 2020 году Фредерик Лау из Китайского университета Гонконга выпустил работу под название «Звуки современности в китайской популярной музыке» (ориг. "The sounds of modernity in Chinese pop music"), в которой он подверг сомнению западные представления о том, что «китайская поп-музыка является производной от западных норм» (Lau, 2020, p. 101). В его статье исследуются вопросы современности, индивидуальности, агентности, творчества, космополитизма и перформативности на фоне становления Китая как современной нации и как глобальной силы. При этом автор пришёл к выводу, что

В самом общем смысле, быть современным в китайском контексте начиналось с упрощённой идеи догнать Запад: смотреть вовне, быть космополитом, прогрессивным и стать гражданином мира, в отличие от традиционности, изоляции, отсталости и регресса, какими представляли Китай западные империалисты. В Китае концепция современности часто работала в тандеме с космополитизмом. Эта синергия мотивировала "улучшение" любого аспекта культуры, который считался устаревшим по сравнению с Западом. В музыке модернистский толчок привёл к широкомасштабному принятию западной музыки в плане прослушивания, исполнения, сочинения, эстетики и моделей потребления (p. 103).

Гибридности китайской музыки посвящена статья Энтони Фунга «Западный стиль, китайская поп-музыка: Рэп Джея Чоу и хип-хоп в Китае» (ориг. "Western Style, Chinese Pop: Jay Chou's Rap and Hip-Hop in China"). Написанная и опубликованная им ещё в 2008 году, статья рассматривает творчество китайского рэпера Джея Чоу в контексте гибридности. Автор отмечает, что

Выступление Джея на сцене также связано с ощущением китайскости. Довольно часто, не перегружая современный, крутой образ, он гибридизирует "крутой" образ с китайской традиционностью (Fung, 2008, p. 74).

Но при этом тут же автор указывает на то, что

Второй уровень китайскости Джея заключается в том, что он является “безопасной" иконой для общества. Джей не героичен, скорее наоборот. Как 
икона крутого поколения он обязан быть скептиком и критиком. В песнях Джея часто затрагивается широкий спектр социальных вопросов (р. 74).

Вопросам цензуры в китайской популярной музыке посвящена работа Иви Мэна, в которой автор рассматривает возможные причины возникновения проблемы цензуры популярной музыки в китайских обществах (Man, 2021).

Китайским телесериалам посвящена работа Шелдон Лу «Мыльная опера в Китае: транснациональная политика визуальности, сексуальности и мужественности» (ориг. "Soap Opera in China: The Transnational Politics of Visuality, Sexuality, and Masculinity"). (Lu, 2000). Проблема маскулинности в китайских сериалах затрагивается целым рядом исследовательских работ. Здесь можно выделить исследования Гэн Сун (Song, 2016), в одной из которых рассматриваются проблемы соотношения мужественного и национального в китайских телесериалах, а в другой (2018) анализируется влияние иностранных представлений о маскулинности (чаще всего западных) на конструирование мужских образов в китайских телепередачах. Также такой исследователь, как Кам Луи затрагивал вопросы маскулинности в популярной культуре Восточной Азии, где, как он утверждает, Китай занимает ведущее место в формировании образа мужественности (Loie, 2012). Влиянию корейской волны (халлю) на китайскую культуру посвящена работа Чан Су Хён (Jang, 2012), а о поп-сцене и национальной идентичности Китая рассказывает в своём исследовании Лицзюань Цянь (Qian, 2017).

Таким образом мы можем наблюдать, что огромный пласт исследовательских работ, посвящённых популярной культуре Китая, затрагивает ряд социокультурных проблем современности.

\section{«Сшей ты мне, матушка, красное ханьфу»}

Мы выбрали именно такой подзаголовок, так как он, на наш взгляд, очень хорошо отражает некоторые процессы, происходящие в современном Китае, где даже в популярной культуре сталкиваются два противоположных явления: традиционализм и новаторство. «Сшей ты мне, матушка, красное ханьфу» это название рецензии российского учёного Сергея Николаевича Якушенкова (2020) на книгу Кевина Каррико «Великая хань: раса, национализм и традиция в современном Китае» (Carrico, 2017). Будучи глобальной силой, с которой считается весь мир, Китай также в индустрии популярной культуры отвоёвывает у своих конкурентов социокультурные пространства других стран и создаёт продукты массовой культуры со свойственными ему (Китаю) ценностями, что очень сильно отличает их от продуктов ближайших соседей - Кореи или Японии.

Для нашего исследования мы провели глобальный опрос российских граждан на предмет их заинтересованности, с одной стороны, в общую азиатскую популярную культуру, а с другой, конкретно в китайскую. Выбрав предметом нашего исследования китайские дорамы, мы поставили перед собой 
цель выявить степень увлечения россиянами этим жанром телесериалов, а также определить долю именно китайских дорам в предпочтениях россиян азиатской массовой культуры в общем.

Составив опросник, мы запустили его в российских социальных сетях. Среди опрошенных были как люди, состоящие в фанатских сообществах по азиатской культуре, так и обычные граждане России. Кроме общих данных (пол, возраст, регион проживания) мы также опросили респондентов об их увлечении общей азиатской культурой, их вовлечённости в прочтение манги, прослушивание К / J / C - pop / rock музыки, увлечение аниме. Помимо этого мы опросили респондентов об их вовлечённости в просмотр азиатских сериалов. При этом для выявления места китайских дорам в предпочтениях россиян помимо вопросов о предмете нашего исследования мы ввели в опросник вопросы по корейским и японским дорамам. Число опрошенных респондентов = 1000 человек (см. таблицу 1). Применяя количественные методы исследования, мы пришли к следующим результатам.

\begin{tabular}{|c|c|c|c|c|c|c|c|c|c|c|c|c|c|}
\hline 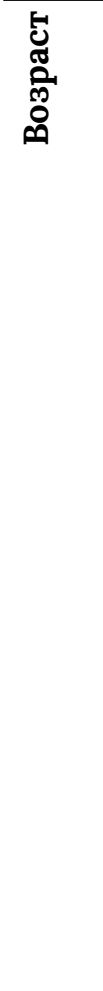 & 占 & 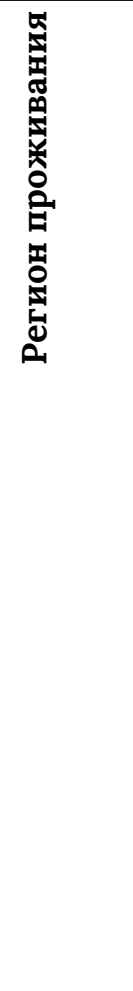 & 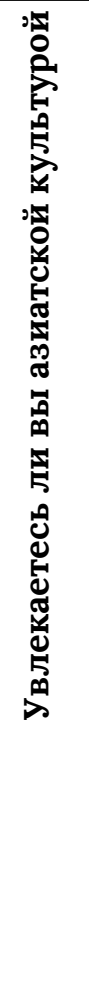 & 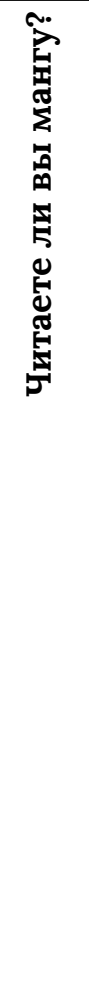 & 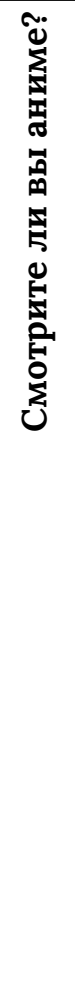 & 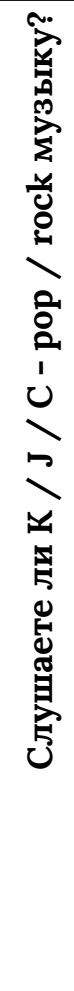 & 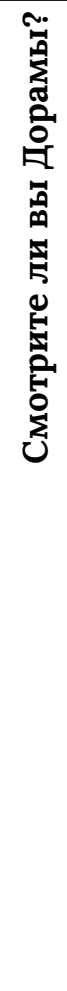 & 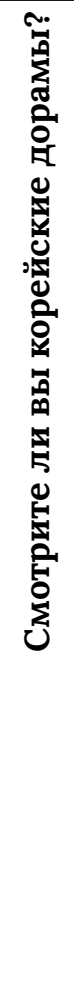 & 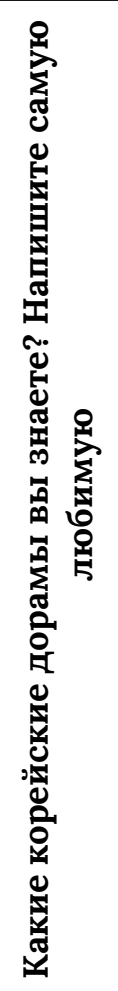 & 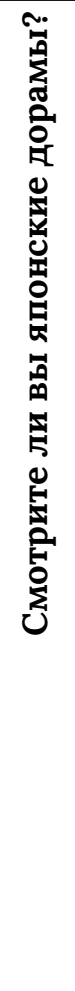 & 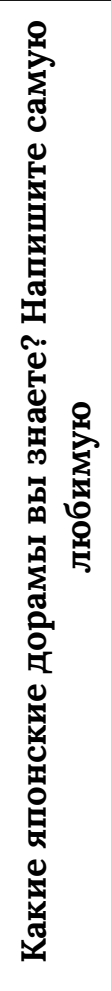 & 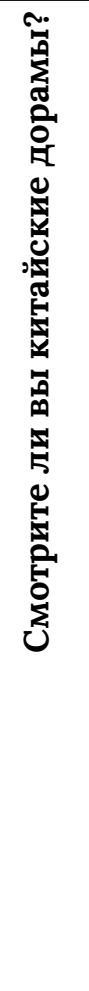 & 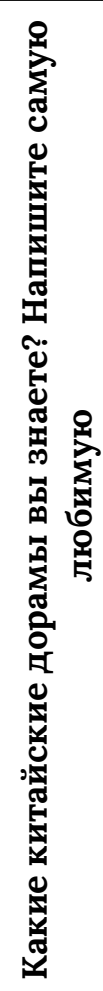 \\
\hline $16-21$ & M & $\begin{array}{l}\text { Ce- } \\
\text { веро- } \\
\text { Запад- } \\
\text { ный }\end{array}$ & Нет & Нет & Да & Да & Да & Да & $\begin{array}{l}\text { Ты } \\
\text { тоже } \\
\text { че- } \\
\text { ло- } \\
\text { век? }\end{array}$ & Да & $\begin{array}{l}\text { Брак } \\
\text { по } \\
\text { конт } \\
\text { ракту }\end{array}$ & Нет & $\begin{array}{l}\text { Не } \\
\text { знаю }\end{array}$ \\
\hline
\end{tabular}




\begin{tabular}{|c|c|c|c|c|c|c|c|c|c|c|c|c|c|}
\hline $34-39$ & M & $\begin{array}{l}\text { Цен- } \\
\text { траль- } \\
\text { ный }\end{array}$ & Нет & Да & Да & Да & Да & Да & $\begin{array}{l}\text { Я } \\
\text { тебя } \\
\text { слы- } \\
\text { шу }\end{array}$ & Да & $\begin{array}{l}\text { Го- } \\
\text { кусэ } \\
\text { н }\end{array}$ & Нет & $\begin{array}{l}\mathrm{He} \\
\text { знаю }\end{array}$ \\
\hline $46-51$ & Ж & $\begin{array}{l}\text { Сибир- } \\
\text { ский }\end{array}$ & Да & Нет & Да & Нет & Да & Да & $\begin{array}{l}\text { Без- } \\
\text { рас- } \\
\text { суд- } \\
\text { но } \\
\text { влюб } \\
\text { лен- } \\
\text { ные }\end{array}$ & Да & $\begin{array}{l}\text { Али- } \\
\text { са в } \\
\text { По- } \\
\text { гра- } \\
\text { ни- } \\
\text { чье }\end{array}$ & Да & $\begin{array}{l}\text { Неу- } \\
\text { кро- } \\
\text { ти- } \\
\text { мый }\end{array}$ \\
\hline
\end{tabular}

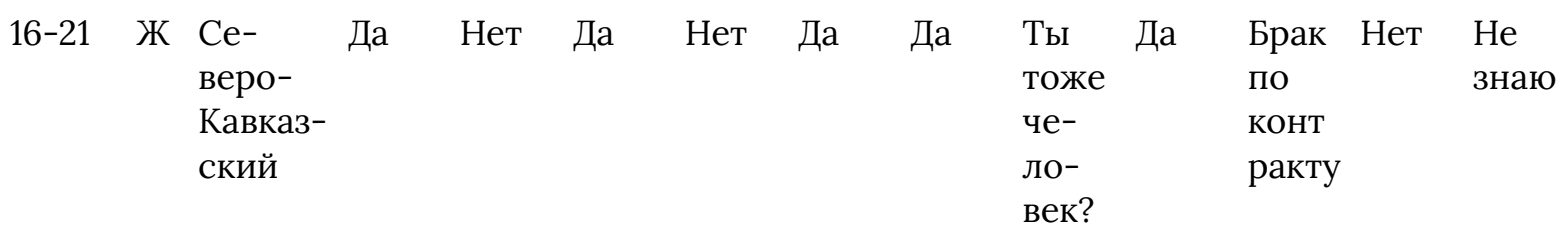

34-39 Ж Сибир- Да Нет Нет Да Нет Нет Не Нет Не Нет Не ский знаю знаю знаю

Таблица 1. Часть опросника, на котором видны ответы респондентов

Table 1. Part of the questionnaire where the answers of respondents can be seen

Возрастной диапазон опрошенных составил от 16 до 51 года, а их количественное соотношение см. на рисунке 2.

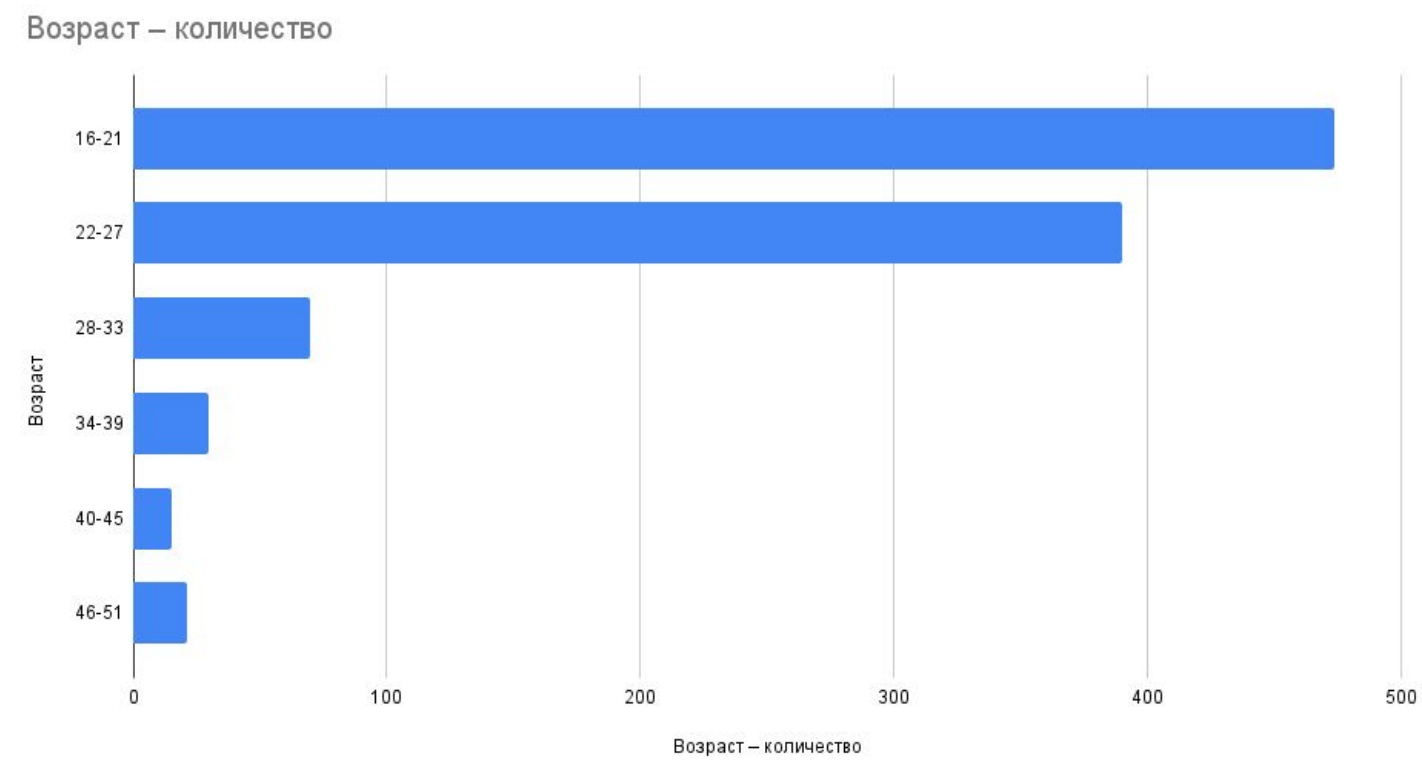

Рисунок 2. Возраст респондентов.

Figure 2. Respondents' age. 
Как мы видим, больше всего среди опрошенных молодые люди в возрасте от 16 до 21 года (более 450 человек). Вторыми по количеству являются опрошенные в возрасте от 22 до 27 лет. Чуть меньше - от 26 до 33 лет. Респонденты старше представлены меньше.

По гендерному признаку распределение опрошенных составило следующее соотношение: респонденты мужского пола - 71,4 \%; женского - 28,6 \% (см. Рисунок 3). Сложно сказать, почему произошло такое распределение, ведь на первый взгляд фанатские сообщества представлены куда большим количеством девушек, чем мужчин в процентном соотношении.

География опрошенных показала более или менее ровное распределение (см. Рисунок 4). Больше всего опрошенных проживают в Дальневосточном, Сибирском и Центральном регионах; наименьшее число респондентов из Приволжского и Северо-Кавказского регионов.

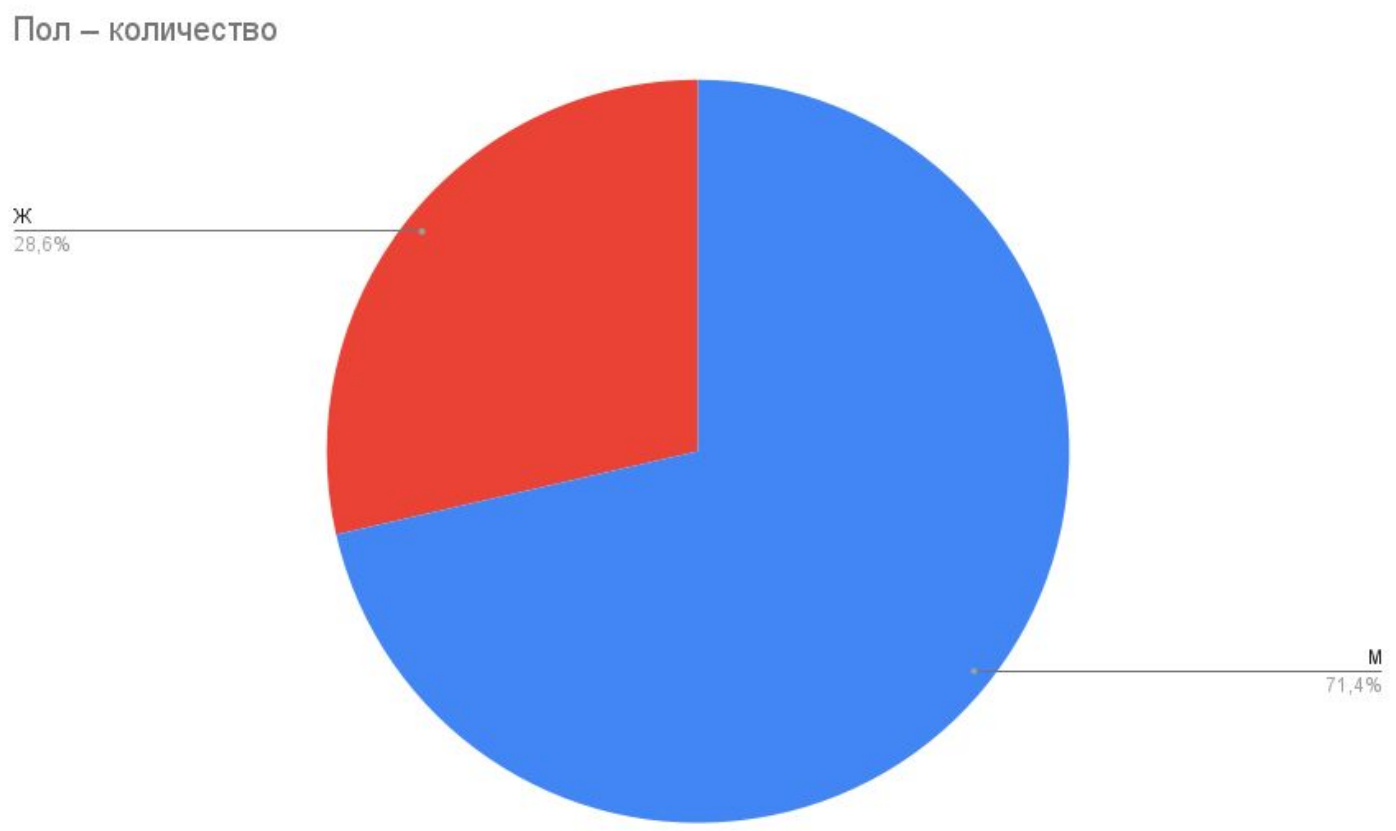

Рисунок 3. Процентное соотношение опрошенных по гендерному признаку

Figure 3. Percentage of respondents by gender 


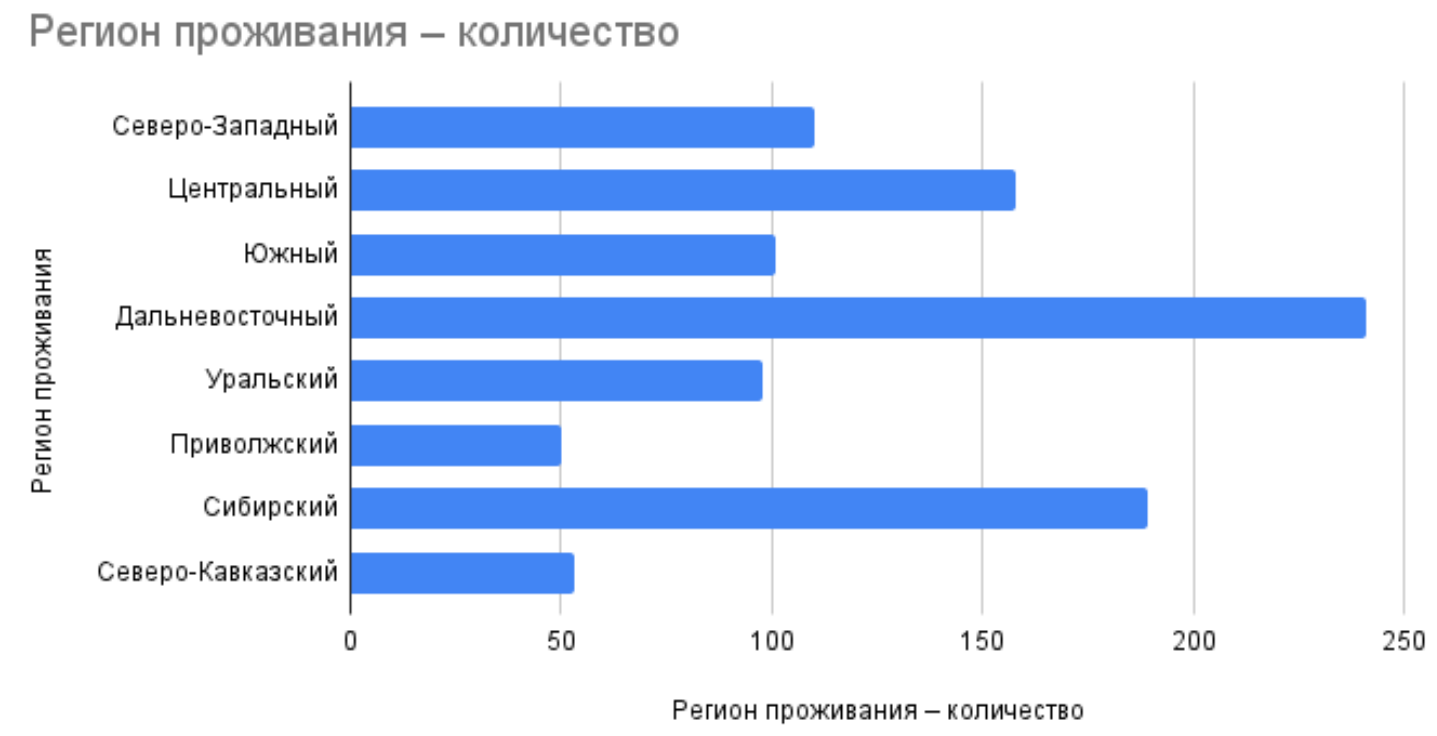

Рисунок 4. География репондентов

Figure 4. The geography of respondents

На вопрос «Увлекаетесь ли вы азиатской культурой» 63,4 \% респондентов дало утвердительный ответ (см. Рисунок 5).

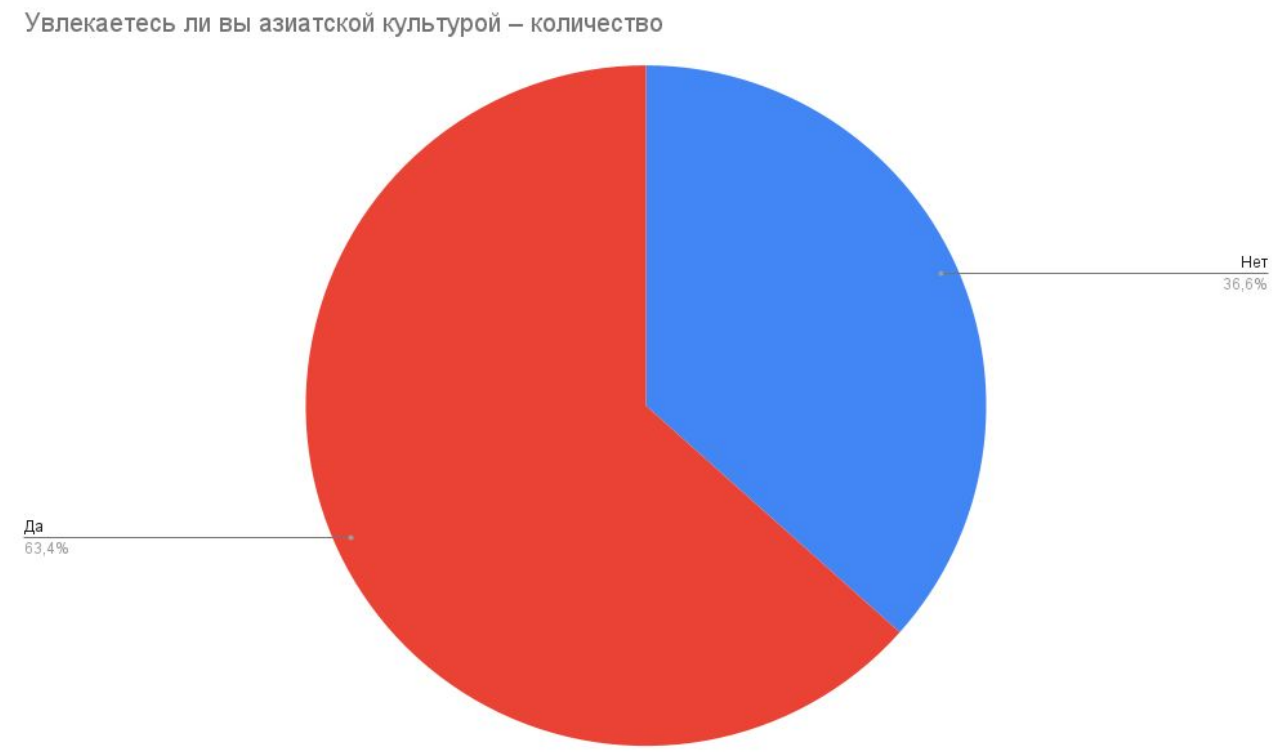

Рисунок 5. Ответы респондентов на вопрос «Увлекаетесь ли вы азиатской культурой»

Figure 5. Answers of respondents to the question "Are you interested in Asian culture?" 
При этом читающих мангу, смотрящих аниме и слушающих К / J / C pop / rock музыку респондентов оказалось меньше (см. Рисунки 6, 7 и 8)

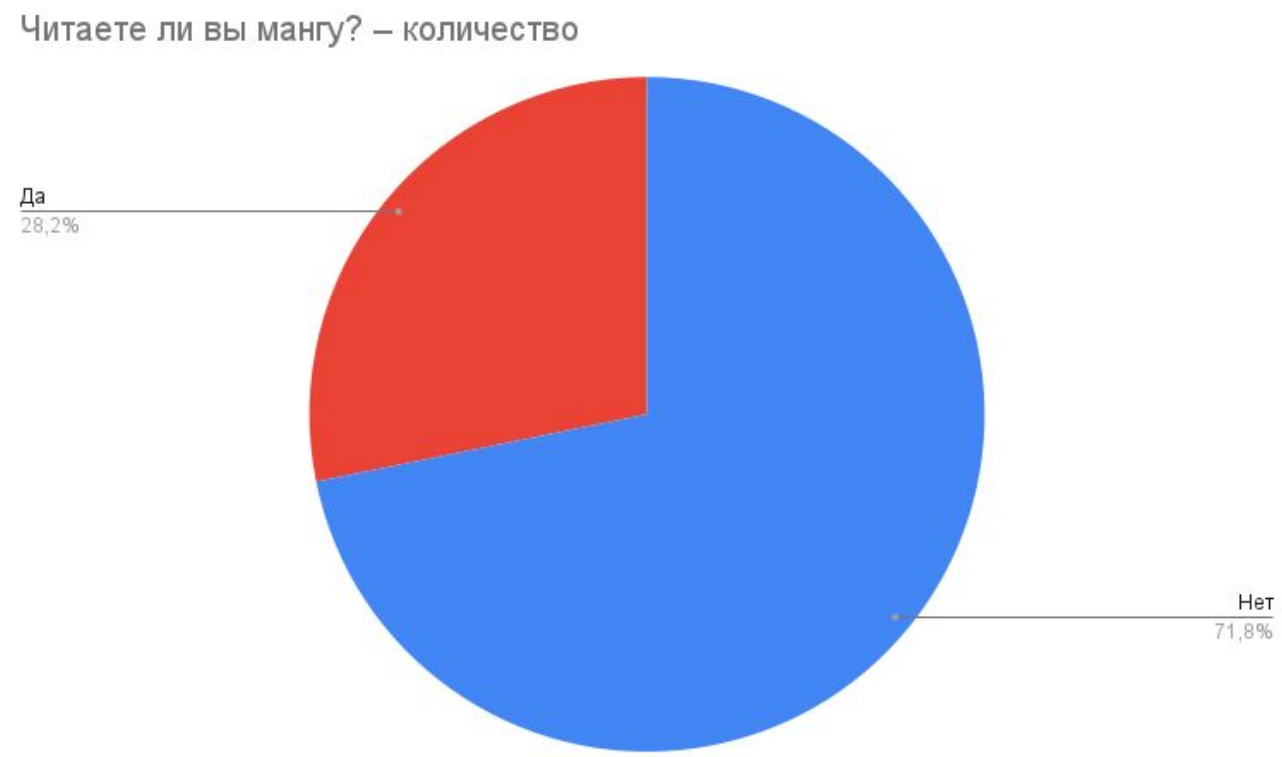

Рисунок 6. Ответы респондентов на вопрос «Читаете ли вы мангу?»

Figure 6. Respondents' answers to the question "Do you read manga?"

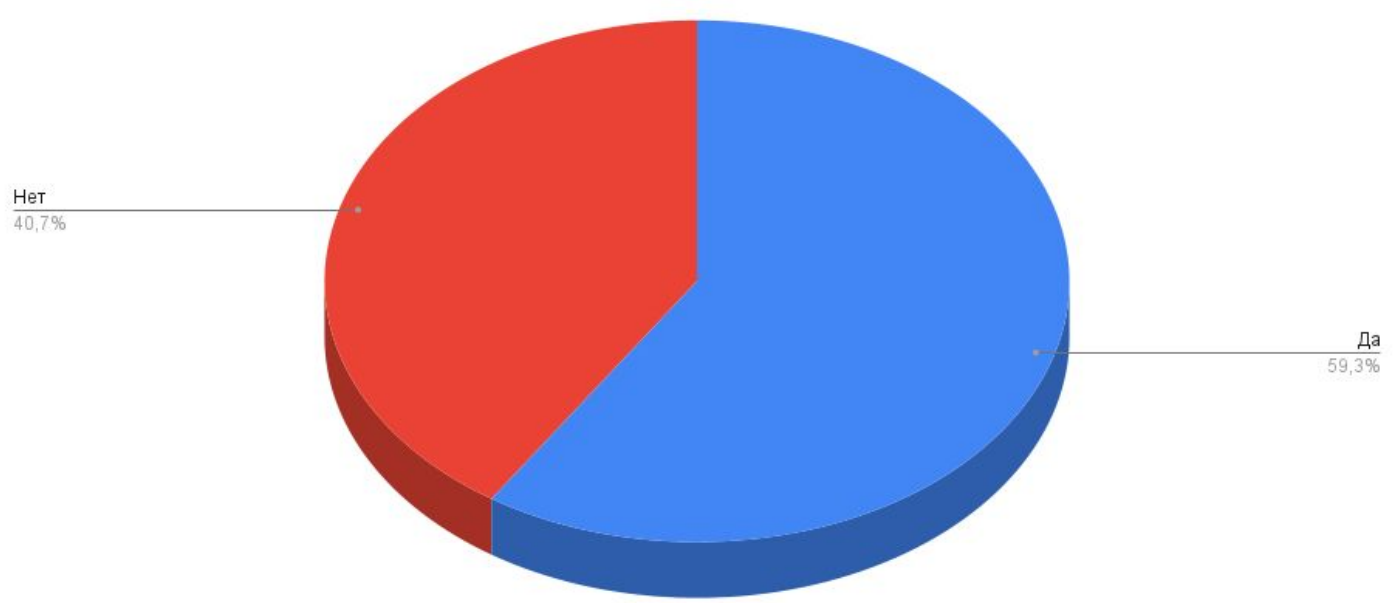

Рисунок 7. Ответы респондентов на вопрос «Смотрите ли Вы аниме?»

Figure 7. Respondents' answers to the question "Do you watch anime?" 


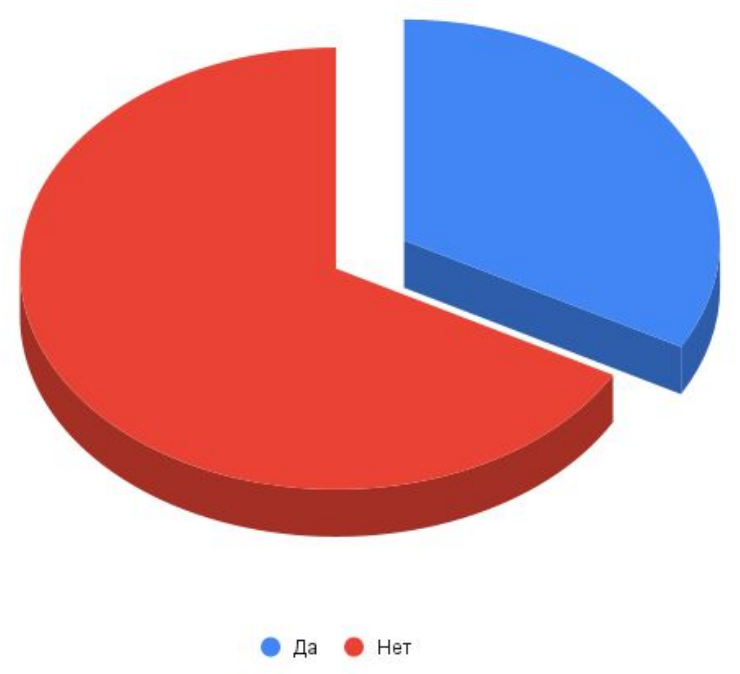

Рисунок 8. Ответы респондентов на вопрос «Слушаете ли Вы К / J / C - pop / rock музыку?»

Figure 8. Respondents' answers to the question "Do you listen to K / J / C - pop / rock music?"

А вот число респондентов, которые смотрят дорамы оказалось выше тех, кто не смотрит их (см. рисунок 9). Мы можем лишь предположить, что это связано с ростом сериальной культуры, доступностью интернета в России и ростом стриминговых сервисов, дающих возможность просмотра телесериалов различных стран мира.

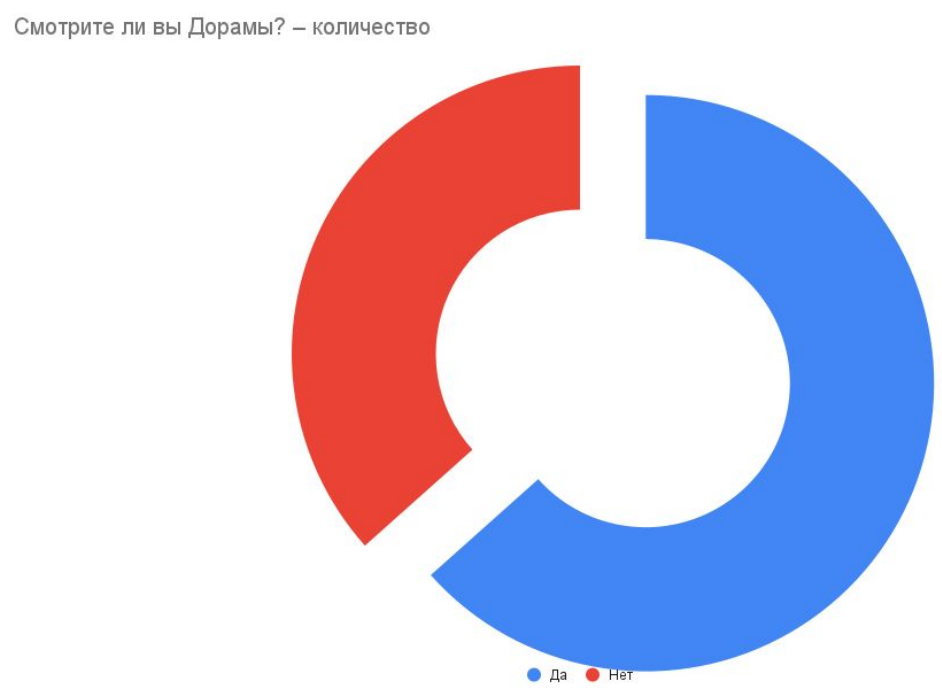

Рисунок 9. Ответы респондентов на вопрос «Смотрите ли вы Дорамы?»

Figure 9. Respondents' answers to the question "Do you watch Doramas?" 
Вопросы следующего блока касались предпочтений дорам конкретных стран (Южная Корея, Япония и КНР). Результаты опроса подтвердили нашу гипотезу о том, что самые популярные дорамы в России - это корейские $(63,4$ \%). Японские дорамы смотрят 47,6 \% опрошенных, а китайские - 23,5 \% респондентов (см. рисунки 10, 11 и 12)

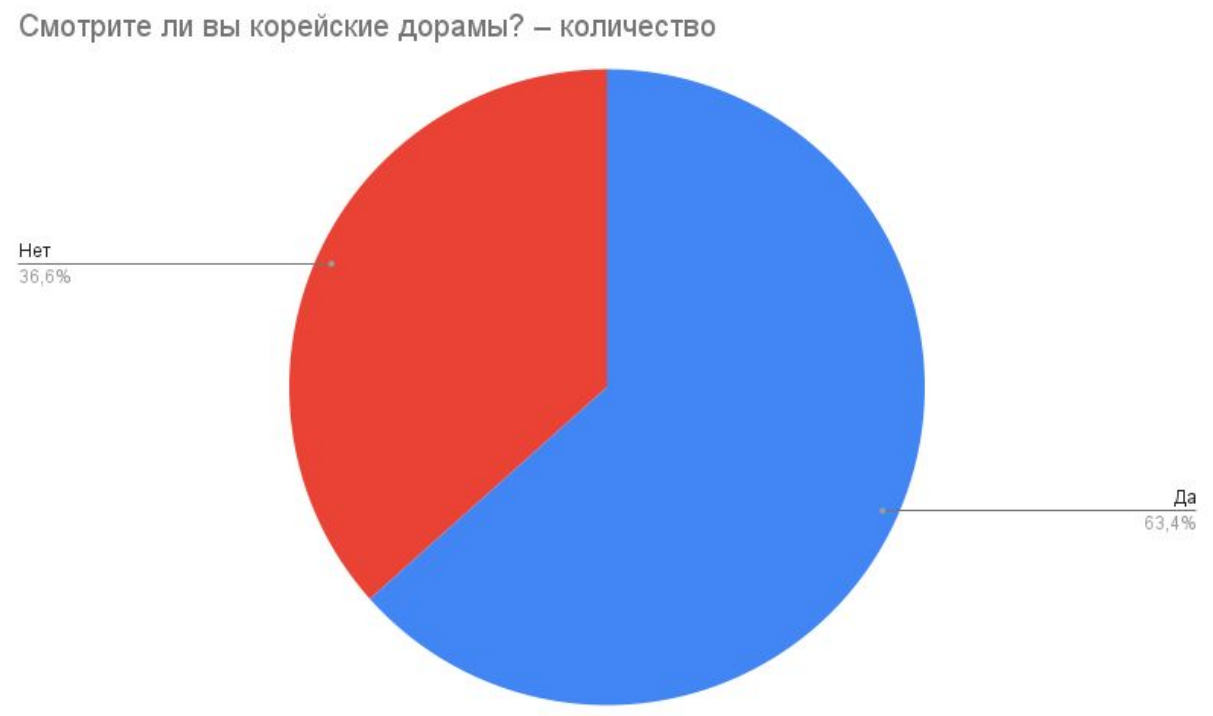

Рисунок 10. Ответы респондентов на вопрос «Смотрите ли вы корейские Дорамы?»

Figure 10. Respondents' answers to the question "Do you watch Korean Doramas?"

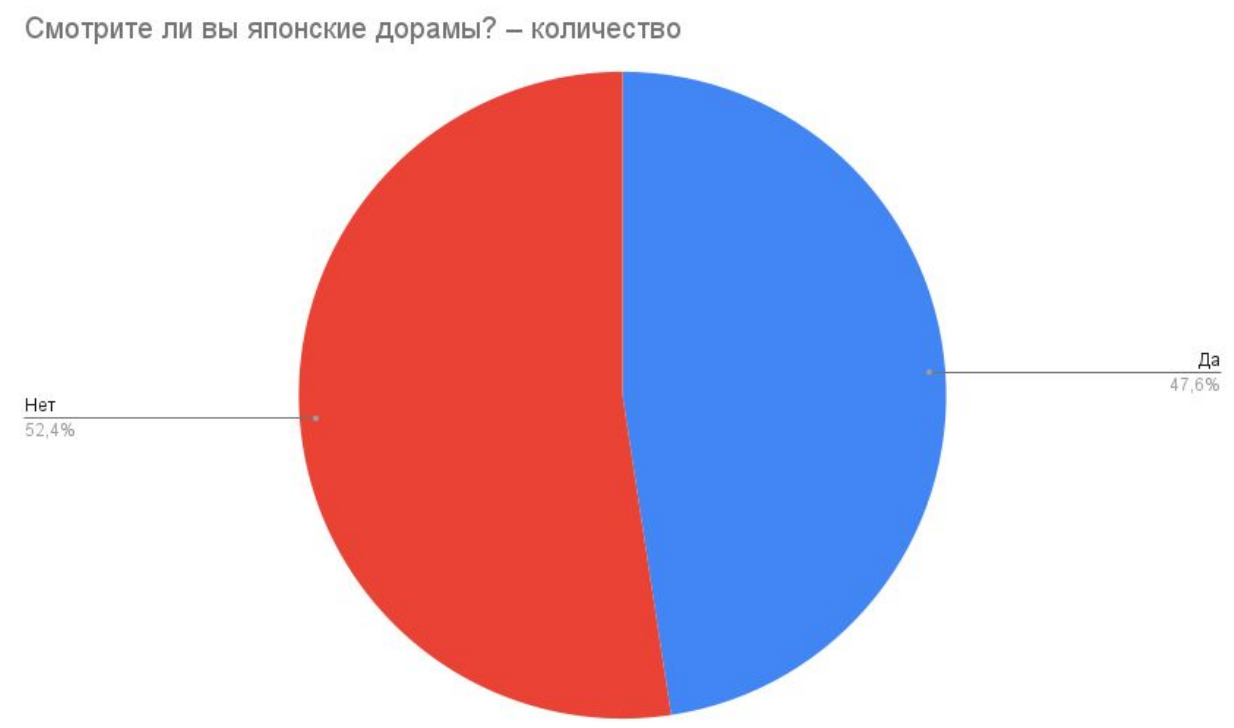

Рисунок 11. Ответы респондентов на вопрос «Смотрите ли вы японские Дорамы?»

Figure 10. Respondents' answers to the question "Do you watch Japanese Doramas?" 


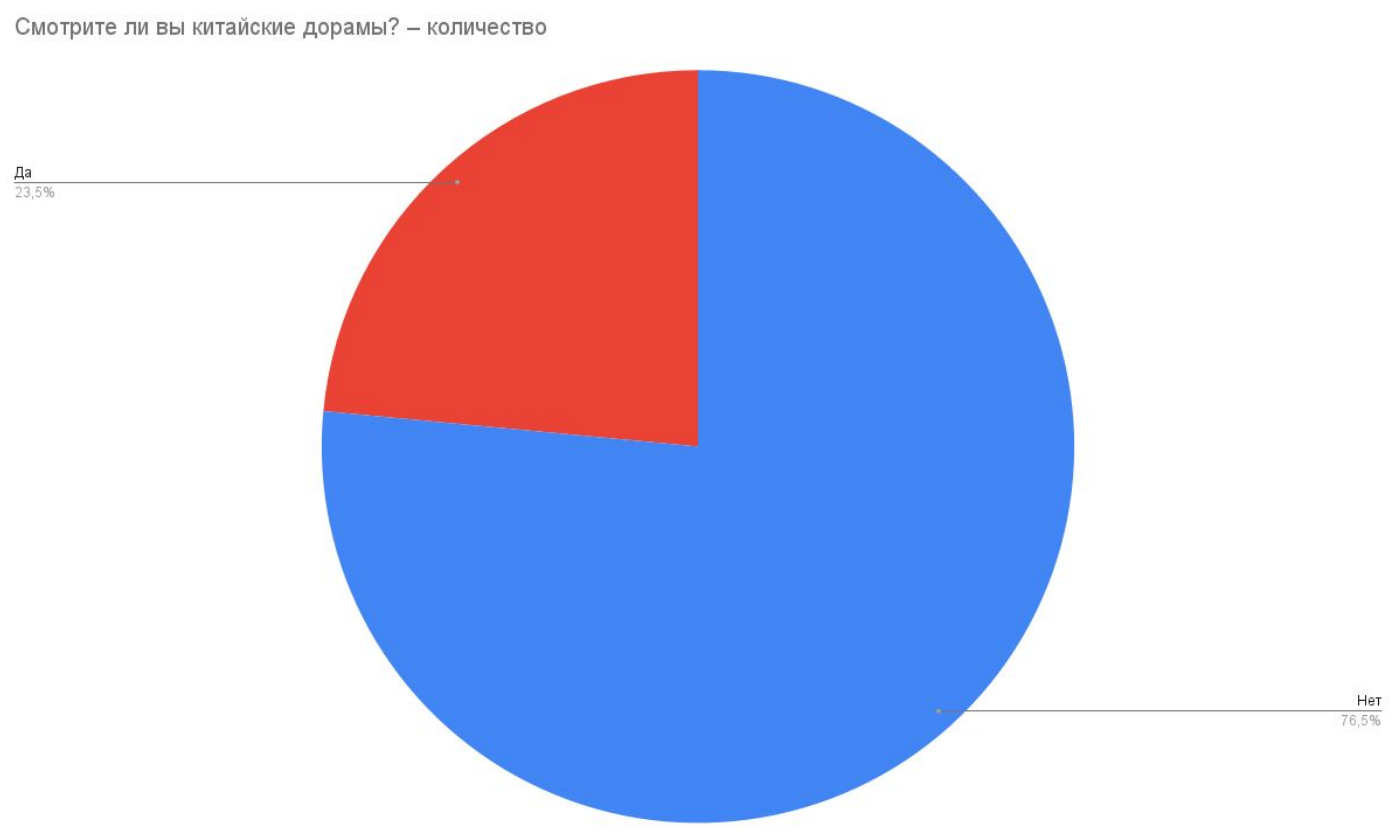

Рисунок 12. Ответы респондентов на вопрос «Смотрите ли вы китайские Дорамы?»

Figure 10. Respondents' answers to the question "Do you watch Chinese Doramas?"

При этом три самых популярных названных китайских дорам это «Неукротимый», «Поразительное на каждом шагу» и «Арсенал военной академии».

\section{Выводы}

Стоит оговориться, что мы не рассматривали содержательную часть китайских дорам в контексте сравнения с корейскими и японскими аналогами в России. К сожалению, это увело бы нас в другую сторону, а сам сравнительный анализ мог бы вылиться в отдельное исследование.

Проведя количественное исследование, прежде всего мы подтвердили нашу гипотезу о том, что китайские дорамы занимают третье место по популярности в российской среде, уступая корейским и японским аналогам. Но при этом фанатские сообщества в России с каждым годом только увеличиваются, а упоминаний китайских дорам в Твиттере и других социальных сетях Рунета становится больше, что говорит о возрастающем потребительском интересе к телевизионной продукции Китая в России. Популярность корейских дорам объясняется тем, что Южная Корея по сути первой из большой тройки Восточноазиатских стран начала экспортировать продукты популярной культуры в другие страны. Перспективы Китая в индустрии телевизионного развлечения кажутся весьма радужными, что позволяет говорить о том, что 
в ближайшем будущем китайские дорамы окончательно обгонят по популярности аналоги из Кореи и Японии.

При этом основной аудиторией азиатских телесериалов остаётся молодёжь в возрасте от 16 до 33 лет, благодаря доступности Интернета, работам фанатских сетевых сообществ и команд энтузиастов, которые делают бесплатные переводы и озвучки популярных дорам в России.

Удивительно, но корреляция между признаками «Увлекаетесь ли вы азиатской культурой» и «Смотрите ли вы дорамы» оказалась сильнее, чем корреляция между признаками ««Увлекаетесь ли вы азиатской культурой» и «Смотрите ли вы аниме / Слушаете ли вы азиатскую популярную музыку / Читаете ли вы мангу». Возможно, что экранная визуализация образов даёт сейчас больше шансов увлечься азиатской культурой, чем рисованные комиксы, анимация и музыка.

Таким образом, говоря о популярности китайских дорам в социокультурном пространстве России, мы можем констатировать факт растущего интереса россиян к данному виду популярной культуры, импортируемой из Китая.

\section{Список литературы}

Carrico, K. (2017). The Great Han: Race, Nationalism, and Tradition in China Today (First edition). Oakland, California: University of California Press.

Fung, A. (2008). Western Style, Chinese Pop: Jay Chou's Rap and Hip-Hop in China. Asian Music, 39(1), 69-80.

Hu, X., \& Yang, Y.-H. (2017). The mood of Chinese Pop music: Representation and recognition. Journal of the Association for Information Science and Technology, 68(8), 1899-1910. doi: $\underline{10.1002 / a s i .23813}$

Jang, S. H. (2012). The Korean Wave and Its Implications for the Korea-China Relationship. Journal of International and Area Studies, 19(2), 97-113.

Lau, F. (2020). The sounds of modernity in Chinese pop music. International Communication of Chinese Culture, 7(2), 101-115. doi: 10.1007/s40636-020-00185-y

Leong, M. (2014, August 2). How Korea became the world's coolest brand. Financial Post. Retrieved from https://financialpost.com/news/retail-marketing/how-korea-became-the-worldscoolest-brand?r

Loie, K. (2012). Popular Culture and Masculinity Ideals in East Asia, with Special Reference to China. The Journal of Asian Studies, 71(4), 929-943.

Lu, Sh. H. (2000). Soap Opera in China: The Transnational Politics of Visuality, Sexuality, and Masculinity. Cinema Journal, 40(1), 25-47.

Man, I. (2021). Popular music censorship under Chinese societies: Selected Canto-pop case studies in China, Hong Kong and Singapore. Asian Education and Development Studies, 10(4), 536-543. doi: 10.1108/AEDS-04-2019-0074 
Ng, E., \& Li, X. (2020). A queer "socialist brotherhood": The Guardian web series, boys' love fandom, and the Chinese state. Feminist Media Studies, 20(4), 479-495. doi: $\underline{10.1080 / 14680777.2020 .1754627}$

Qian, L. (2017). Which Identity Matters? Competing Ethnicities in Chinese TV Music Contests. The World of Music, 6(2), 57-82.

Song, G. (2016). All Dogs Deserve to Be Beaten: Negotiating Manhood and Nationhood in Chinese TV Dramas. In K. Louie, D. Hird, \& G. Song (Eds.), Changing Chinese Masculinities: From Imperial Pillars of State to Global Real Men (1st ed., Vol. 1, pp. 204-219). Hong Kong University Press.

Song, G. (2018). Cosmopolitanism with Chinese Characteristics: Transnational Male Images in Chinese TV Dramas. In D. Hird \& G. Song (Eds.), The Cosmopolitan Dream: Transnational Chinese Masculinities in a Global Age (1st ed.). Hong Kong University Press. doi: 10.2307/j.ctv80cbgs

Whang, H., Yong, S., \& Ko, E. (2016). Pop culture, destination images, and visit intentions: Theory and research on travel motivations of Chinese and Russian tourists. Journal of Business Research, 69(2), 631-641. doi: 10.1016/i.jbusres.2015.06.020

Сериалы 2020 года (Китай) - списки лучших сериалов. (2020). Извлечено от КиноПоиск website: https://www.kinopoisk.ru/lists/navigator/2020/country-31/?quick_filters=serials\&tab=all

Якушенков, С. Н. (2020). Сшей ты мне, матушка, красное ханьфу. Corpus Mundi, 1(4), 102-107. doi: $\underline{10.46539 / \mathrm{cmj} . v 1 i 4.35}$

Якушенкова, О. С., \& Алиев, Р. Т. (2020). К/Ј/С-Рор и образы «азиатскости» в российском сегменте Интернет: Вебометрический анализ. Galactica Media: Journal of Media Studies, 2(4), 187-213. doi: 10.46539/gmd.v2i4.141

\section{Reference}

Carrico, K. (2017). The Great Han: Race, Nationalism, and Tradition in China Today (First edition). Oakland, California: University of California Press.

Fung, A. (2008). Western Style, Chinese Pop: Jay Chou's Rap and Hip-Hop in China. Asian Music, 39(1), 69-80.

Hu, X., \& Yang, Y.-H. (2017). The mood of Chinese Pop music: Representation and recognition. Journal of the Association for Information Science and Technology, 68(8), 1899-1910. doi: $\underline{10.1002 / a s i .23813}$

Jang, S. H. (2012). The Korean Wave and Its Implications for the Korea-China Relationship. Journal of International and Area Studies, 19(2), 97-113.

Lau, F. (2020). The sounds of modernity in Chinese pop music. International Communication of Chinese Culture, 7(2), 101-115. doi: 10.1007/s40636-020-00185-y

Leong, M. (2014, August 2). How Korea became the world's coolest brand. Financial Post. Retrieved from https://financialpost.com/news/retail-marketing/how-korea-became-the-worldscoolest-brand?r

Loie, K. (2012). Popular Culture and Masculinity Ideals in East Asia, with Special Reference to China. The Journal of Asian Studies, 71(4), 929-943.

Lu, Sh. H. (2000). Soap Opera in China: The Transnational Politics of Visuality, Sexuality, and Masculinity. Cinema Journal, 40(1), 25-47. 
Man, I. (2021). Popular music censorship under Chinese societies: Selected Canto-pop case studies in China, Hong Kong and Singapore. Asian Education and Development Studies, 10(4), 536-543. doi: 10.1108/AEDS-04-2019-0074

Ng, E., \& Li, X. (2020). A queer "socialist brotherhood": The Guardian web series, boys' love fandom, and the Chinese state. Feminist Media Studies, 20(4), 479-495. doi: $\underline{10.1080 / 14680777.2020 .1754627}$

Qian, L. (2017). Which Identity Matters? Competing Ethnicities in Chinese TV Music Contests. The World of Music, 6(2), 57-82.

Song, G. (2016). All Dogs Deserve to Be Beaten: Negotiating Manhood and Nationhood in Chinese TV Dramas. In K. Louie, D. Hird, \& G. Song (Eds.), Changing Chinese Masculinities: From Imperial Pillars of State to Global Real Men (1st ed., Vol. 1, pp. 204-219). Hong Kong University Press.

Song, G. (2018). Cosmopolitanism with Chinese Characteristics: Transnational Male Images in Chinese TV Dramas. In D. Hird \& G. Song (Eds.), The Cosmopolitan Dream: Transnational Chinese Masculinities in a Global Age (1st ed.). Hong Kong University Press. doi: 10.2307/j.ctv80cbgs

Whang, H., Yong, S., \& Ko, E. (2016). Pop culture, destination images, and visit intentions: Theory and research on travel motivations of Chinese and Russian tourists. Journal of Business Research, 69(2), 631-641. doi: 10.1016/j.jbusres.2015.06.020

TV Series of 2020 (China) - Best TV Series Lists. (2020). Retrieved from Kinopoisk website: https://www.kinopoisk.ru/lists/navigator/2020/country-31/?quick_filters=serials\&tab=all (In Russian).

Yakushenkov, S. N. (2020). Sew Me, Mom, Red Hanfu. Corpus Mundi, 1(4), 102-107. doi: $\underline{10.46539 / \mathrm{cmj} . v 1 i 4.35}$ (In Russian).

Yakushenkova, O. S., \& Aliev, R. T. (2020). K/J/C-Pop and Images of "Asianness" in the Russian Internet Segment: Webometric Analysis. Galactica Media: Journal of Media Studies, 2(4), 187-213. doi: 10.46539/gmd.v2i4.141 (In Russian). 